\title{
Análise da atividade antimicrobiana de probióticos e sua adesividade a bráquetes ortodônticos: estudo in vitro
}

\author{
Analysis of probiotic antimicrobial activity and its adherence to orthodontic \\ brackets: in vitro study \\ Thayse Caroline de Abreu BRANDI ${ }^{a}$ (D), Amanda Nunes MONTEIROa (i),

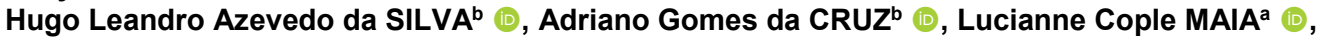 \\ Matheus Melo PITHONa,c* [D \\ aUFRJ - Universidade Federal do Rio de Janeiro, Faculdade de Odontologia, Departamento de Odontopediatria e \\ Ortodontia, Rio de Janeiro, RJ, Brasil \\ 'Instituto Federal de Ciências e Tecnologia do Rio de Janeiro, Rio de Janeiro, RJ, Brasil \\ 'UESB - Universidade Estadual do Sudoeste da Bahia, Departamento de Saúde I, Jequié, BA, Brasil
}

\begin{abstract}
Como citar: Brandi TCA, Monteiro AN, Silva HLA, Cruz AG, Maia LC, Pithon MM. Análise da atividade antimicrobiana de probióticos e sua adesividade a bráquetes ortodônticos: Estudo in vitro. Rev Odontol UNESP. 2019;48:e20190092. https://doi.org/10.1590/1807-2577.09219
\end{abstract}

\begin{abstract}
Resumo
Introdução: A presença de aparelho ortodôntico fixo dificulta a higienização e potencializa o acúmulo de biofilme bacteriano nas superfícies dentárias. 0 desenvolvimento de produtos que minimize isso é desejo de pesquisadores em todo o mundo. Objetivo: Verificar a ação bacterapêutica de produtos lácteos contendo ou não probióticos sob pool de Streptococcus mutans (SM) (ATCC 25175) e S salivarius (SS) (ATCC 7073), além da adesão desses produtos à superfície de bráquetes ortodônticos. Material e método: Pool de cepas ATCC de SM e SS foi formado e plaqueado sobre placa de Petri contendo meio de cultura brain heart infusion ágar (BHI). Após formação do meio, um orifício foi feito no centro da placa seguido do seu preenchimento com $150 \mu \mathrm{L}$ dos produtos a serem testados, formando os seguintes grupos: GL - Leite bovino; GLP - Leite bovino com probiótico; GLF - Leite fermentado; e GLFP - Leite fermentado com probiótico. Na sequência, as placas foram incubadas por $48 \mathrm{~h}$, em estufa a $37^{\circ} \mathrm{C}$. A seguir, foi feita a medição do halo formado entre o produto e o meio com régua milimetrada. Já no disco de membrana, foi formado biofilme com o mesmo pool de cepas, sob discos de membrana. Em seguida, foi feita a diluição seriada contendo o produto de acordo com o grupo: P1 (água); P2 (L); P3 (LP); P4 (LFP), seguida do plaqueamento e a contagem total de micro-organismos. Para a adesividade dos produtos lácteos, bráquetes ortodônticos foram submergidos em cada solução (GL, GLP, GLF e GLFP) e foram incubadas a $37^{\circ} \mathrm{C} / 24 \mathrm{~h}$. Posteriormente, cada bráquete foi transferido para um ependorf contendo solução salina estéril, que foi submetida a diluições seriadas, posteriormente incubadas a $37^{\circ} \mathrm{C} / 48 \mathrm{~h}$ sob microaerofilia para contagem das UFC/mL. Para análise dos dados, utilizaram-se os testes Levene, Shapiro-Wilk e Kruskal-Wallis. 0 nível de significância adotado foi de $5 \%(\alpha=0,05)$. Resultado: Não houve formação de halo de inibição entre os produtos e o meio de cultura $(\mathrm{p}<0,05)$; no disco de membrana, não foram observadas diferenças estatísticas entre os grupos $(\mathrm{p}=0,679)$; os grupos tratados com leite bovino com probiótico e leite fermentado com probiótico apresentaram adesividade aos bráquetes ortodônticos $(\mathrm{p}=0,056)$. Conclusão: Os achados do presente estudo permitem concluir que, em estudos in vitro, não foi possível verificar a bacterioterapia a partir de produtos lácteos contendo ou não probióticos em cepas de SM e SS.
\end{abstract}

Descritores: Disco de membrana; halo de inibição; adesividade; bráquetes; probióticos.

\section{Abstract}

Introduction: The presence of a fixed orthodontic appliance makes cleaning difficult and enhances the accumulation of bacterial biofilm on dental surfaces. It is the desire of researchers worldwide. Objective: To verify the bacteriotherapeutic action of dairy products containing or not probiotics under 
Streptococcus mutans (SM) (ATCC 25175) and S salivarius (SS) (ATCC 7073) pools, as well as their adhesion to the surface of orthodontic brackets. Material and method: Pool of SM and SS ATCC strains was formed and plated on a petri dish containing brain heart infusion agar (BHI) culture medium. After formation of the medium a hole was made in the center of the plate followed by filling with $150 \mu \mathrm{L}$ of the products to be tested, forming the following groups: GL - Bovine milk; GLP - Probiotic bovine milk; GLF - Fermented milk and GLFP - Probiotic fermented milk. Following the plates were incubated for $48 \mathrm{~h}$ in an oven at $37^{\circ} \mathrm{C}$. After that the halo formed between the product and the medium was measured with a millimeter ruler. Already in the membrane disc was formed biofilm with the same pool of strains, under membrane discs. After this the serial dilution containing the product was made according to the group: P1 (water); P2 (L); P3 (LP); P4 (LFP), followed by plating and total microorganism count. For the adhesiveness of dairy products, orthodontic brackets were submerged in each solution (GL, GLP, GLF and GLFP), which were incubated at $37^{\circ} \mathrm{C} / 24 \mathrm{~h}$. Subsequently, each bracket was transferred to an ependorf containing sterile saline solution, which was subjected to serial dilutions, then incubated at $37^{\circ} \mathrm{C} / 48 \mathrm{~h}$ under microaerophilia for counting CFU/mL. For data analysis, the Levene, Shapiro-Wilk and KruskalWallis tests were used. The adopted significance level was $5 \%(\alpha=0.05)$. Result: There was no inhibition halo formation between the products and the culture medium $(\mathrm{p}<0.05)$; In the membrane disc no statistical differences were observed between the groups $(\mathrm{p}=0.679)$; The group treated with probiotic bovine milk and probiotic fermented milk showed adherence to orthodontic brackets $(\mathrm{p}=0.056)$. Conclusion: The findings of the present study allow us to conclude that, in in vitro studies, it was not possible to verify bacteriotherapy from dairy products containing or not probiotics in SM and SS strains.

Descriptors: Membrane disc; halo inhibition; adhesiveness; brackets; probiotics.

\section{INTRODUÇÃO}

A presença de aparelho ortodôntico fixo dificulta a higienização e potencializa o acúmulo de biofilme bacteriano nas superfícies dentárias ${ }^{1,2}$ cujas bactérias produzem ácidos a partir da fermentação dos restos alimentares, levando ao processo carioso por meio da desmineralização dos cristais de hidroxiapatita do esmalte dentário ${ }^{3,4}$. Gera-se, assim, um desequilíbrio entre os processos de desmineralização e remineralização desempenhados pela saliva.

Apesar dos avanços na área da prevenção da cárie, evitar a desmineralização ao redor dos bráquetes ortodônticos, ainda é um desafio a ser enfrentado ${ }^{5}$. Na presença dos acessórios ortodônticos, o biofilme dental tem sua natureza alterada ocasionando um aumento significante na população de Estreptococos e Lactobacilos6. O Streptococcus mutans é considerado o microrganismo que apresenta maior relevância nesse processo, sendo descrito como agente etiológico da cárie dentária, pois promove a produção de ácidos e é capaz de produzir polissacarídeos extracelulares ${ }^{6}$. A busca de uma terapêutica que reduza a população desses micro-organismos é anseio da comunidade científica em todo o mundo, haja vista as repercussões negativas que a cárie promove nos indivíduos. Aplicação de flúor nas mais variadas formas, uso de colutórios contendo agentes bactericidas são algumas maneiras de minimizar o processo, entretanto esses apresentam efeitos colaterais muitas vezes indesejáveis. Nos dias atuais, existe uma preocupação muito grande quanto à necessidade de se desenvolver terapêuticas que, ao invés de agir por si só, auxiliem o organismo a se defender. Dessa forma, os probióticos tornaram-se evidência em diversos ramos da saúde ${ }^{7}$.

Probiótico é definido pela Organização Mundial da Saúde como sendo microrganismos vivos que quando administrados em quantidades adequadas conferem benefícios à saúde do hospedeiro ${ }^{8}$. A administração oral de probióticos beneficia a saúde bucal, evitando o crescimento da microbiota danosa à saúde oral ${ }^{9}$.

Nessa perspectiva, surgem alguns questionamentos, será que os leites bovino e fermentado, contendo probiótico, teriam ação terapêutica diante de biofilme misto de $S$. mutans e S. salivarius e adesão aos bráquetes ortodônticos? Esse trabalho se propôs a verificar a hipótese de que a presença de probiótico conferiria aos leites poder bacterapêutico. 


\section{MATERIAL E MÉTODO}

\section{Atividade Antibacteriana}

\section{Formação do Inóculo}

0 inóculo foi constituído de um pool com $1,5 \times 10^{8}$ células $/ \mathrm{ml}$ de Streptococcus mutans (ATCC 25175) e Streptococcus salivarius (ATCC 7073), mantidas a $-80^{\circ} \mathrm{C}$ e foram reativas em placas de BHI, sob microaerofilia, em estufa a $37^{\circ} \mathrm{C}$ por 48 horas. Posteriormente a densidade óptica observada foi conferida em espectofotômetro (Biospectro SP-220 UV-VIS spectrophotometer, Equipar Ltda., Curitiba, Brazil) com turbidez variando entre 0,08 e 0,12, equivalente a uma solução padrão na escala 0,5 McFarland.

\section{Plaqueamento e Formação do Halo}

O pool de cepas ATCC de Streptococcus mutans e Streptococcus salivarius foi formado e plaqueado com a ajuda de um swab estéril, sobre placa de Petri contendo meio de cultura brain heart infusion ágar (BHI). Em seguida, criou-se um orifício no centro da placa utilizando-se o maior forame de uma ponteira de pipeta estéril. 0 meio Ágar foi removido com auxílio de uma ponta de agulha. Para selar o fundo da placa, foram colocados $100 \mu \mathrm{L}$ de ágar-ágar $\left(56^{\circ} \mathrm{C}\right)$ sem encostar no fundo da placa ou no BHI; este conjunto ficou sob refrigeração $\left(10^{\circ} \mathrm{C}\right)$ por $10 \mathrm{~min}$.

0 poço de cada placa foi preenchido com $150 \mu \mathrm{L}$ dos produtos a serem testados, de acordo com os grupos a serem avaliados (Tabela 1).

Tabela 1. Grupos avaliados nos testes de formação do halo de inibição e no teste de aderência

\begin{tabular}{cc}
\hline Grupos & Produtos avaliados \\
\hline GL & Leite bovino \\
GLP & Leite bovino com probiótico \\
GLF & Leite fermentado \\
GLFP & Leite fermentado com probiótico \\
\hline
\end{tabular}

As placas foram então incubadas por $24 \mathrm{~h}$, em estufa a $37^{\circ} \mathrm{C}$. A seguir, foi feita a medição do halo formado com régua milimetrada. 0 experimento foi realizado em triplicata.

\section{Disco de Membrana}

\section{Formação do Inóculo}

Para o teste de disco de membrana, a formação do inóculo foi idêntica quando da realização ao halo de inibição.

\section{Formação do Biofilme em Membrana e Diluição Seriada}

Em placas contendo $20 \mathrm{ml}$ de BHI ágar (Difco, Sparks, EUA), com auxílio de pinças estéreis, foram inseridas em discos de membranas $(0,13 \mathrm{~mm}$ de diâmetro) (Millipore), previamente autoclavadas. Posteriormente, foram adicionados $40 \mu \mathrm{L}$ do inóculo ao centro da membrana. 0 conjunto foi inoculado por $48 \mathrm{hr}$, em microaerofilia, na estufa a $37^{\circ} \mathrm{C}$. 
A membrana contendo o biofilme formado foi levada a ependorf contendo $1 \mathrm{~mL}$ dos produtos controle e experimentais, como descrito na Tabela 2:

Tabela 2. Grupos avaliados no teste de disco de membrana

\begin{tabular}{cc}
\hline Grupos & Produtos avaliados \\
\hline P1 & Controle negativo (água) \\
P2 & Controle positivo (L) \\
P3 & Leite com probiótico \\
P4 & Leite fermentado com probiótico \\
\hline
\end{tabular}

A membrana ficou em repouso por 5 min e, posteriormente, foi agitada mecanicamente por 1 min (momento 0). Em seguida, iniciou-se diluição seriada, com a remoção de $100 \mu \mathrm{L}$ e adicionado a $900 \mu \mathrm{L}$ de solução salina e agitado por 30 segundos (momento 1). Esse processo foi repetido em 8 momentos. 0 tratamento e a diluição foram realizados em duplicata.

Os momentos 5, 6, 7 e 8 foram plaqueados em triplicata, com o auxílio de alça Drigaus em placas contendo $20 \mathrm{ml}$ de BHI ágar (Difco, Sparks, EUA), e incubados por $48 \mathrm{~h}$, em microaerofilia, na estufa a $37^{\circ} \mathrm{C}$. Foi feita, então, a contagem total dos micro-organismos por grupo.

\section{Teste de Aderência}

\section{Adesão dos Produtos Lácteos aos Bráquetes}

Os bráquetes ortodônticos (Edgewise Slim REF 10.65.203, Sorocaba, São Paulo, Brasil), previamente esterilizados, foram colocados com o auxílio de pinça estéril em Ependorfs, contendo os produtos a serem testados, em duplicada. Os produtos foram divididos de acordo com o grupo (Tabela 1). 0 ependorf contendo o conjunto (Bráquetes+Produto) ficou incubado por $24 \mathrm{~h}$, em estufa a $37^{\circ} \mathrm{C}$.

\section{Diluição Seriada e Plaqueamento}

Após o período de incubação, os bráquetes foram removidos dos produtos, imersos em $1000 \mu \mathrm{L}$ de solução salina e agitados mecanicamente por 3 min (momento 0). Iniciou-se, então, diluição seriada, com a remoção de $100 \mu \mathrm{L}$ e adicionado a $900 \mu \mathrm{L}$ de solução salina e agitado por 30 segundos (momento 1). Esse processo foi repetido em 3 momentos. 0 tratamento e as diluições foram feitos em duplicata.

Os momentos 1, 2 e 3 foram plaqueadas em triplicata, pela técnica de gota em placas contendo $20 \mathrm{ml}$ de BHI ágar (Difco, Sparks, EUA), a seguir, fez-se a contagem total dos micro-organismos.

\section{Análise Estatística}

Para análise dos dados dos testes de disco de membrana e adesividade dos produtos lácteos, inicialmente foram verificados os pressupostos para utilização da análise de variância de um fator (ANOVA one-way): homocedasticidade e normalidade. A homocedasticidade foi testada pelo teste de Levene e a normalidade pelo teste de Shapiro-Wilk. No caso em que esses pressupostos não foram atendidos, procedeu-se ao teste Kruskal-Wallis. 0 nível de significância adotado foi de $5 \%(\alpha=0,05)$. Os dados foram tabulados e analisados no IBM SPSS Statistics para Windows (IBM SPSS. 21.0, 2012, 
Armonk, NY: IBM Corp.). Para análise do teste de halo de inibição, não foi feito nenhum teste estatístico, pois, em nenhum grupo, foi formado o halo de inibição.

\section{RESULTADO}

Para o teste de formação de halo de inibição, não foi formado nenhum halo em nenhum dos grupos. Não foram observadas diferenças significativas entre os grupos nos testes de disco de membrana (Tabela 3) e adesividade dos produtos lácteos (Tabela 4).

Tabela 3. Teste de disco de membrana

\begin{tabular}{cccc}
\hline Grupo & Mediana & Mínimo & Máximo \\
\hline P1 & $7,80 \times 10^{-4}$ & $7,50 \times 10^{-4}$ & $9,76 \times 10^{-4}$ \\
P2 & $4,11 \times 10^{-4}$ & $2,19 \times 10^{-4}$ & $8,41 \times 10^{-4}$ \\
P3 & $3,91 \times 10^{-4}$ & $3,02 \times 10^{-4}$ & $63,00 \times 10^{-4}$ \\
P4 & $2,91 \times 10^{-4}$ & $0,55 \times 10^{-4}$ & $55,20 \times 10^{-4}$ \\
\hline
\end{tabular}

P1, água (controle negativo); P2, leite bovino sem probiótico (controle positivo); P3, leite bovino com probiótico; P4, leite fermentado com probiótico. ${ }^{*}$ Teste Kruskal-Wallis.

Tabela 4. Teste de adesividade dos produtos lácteos

\begin{tabular}{cccc}
\hline Grupo & Média & Desvio padrão & *p-valor \\
\hline GL & 0,00 & 0,00 & \\
GLP & $76,20 \times 10^{-2}$ & $41,86 \times 10^{-2}$ & 0,056 \\
GLF & 0,00 & 0,00 & \\
GLFP & $44,01 \times 10^{-2}$ & $6,14 \times 10^{-2}$ & \\
\hline
\end{tabular}

GL, leite bovino; GLP, leite bovino com probiótico; GLF, leite fermentado; GLFP, leite fermentado com probiótico. *ANOVA one-way.

Neste estudo, não foi possível observar adesividade ao bráquete pelos produtos do tipo leite bovino como é possível observar pela Tabela 4. Já no GLP e GLFP (leite bovino e leite fermentado com probiótico, respectivamente), foi observado que havia micro-organismo aderido aos bráquetes.

\section{DISCUSSÃO}

Já está bem descrito e documentado na literatura o aumento no acúmulo de biofilme bacteriano em pacientes portadores de aparelho ortodôntico fixo. A presença do biofilme favorece a desmineralização e o aparecimento das manchas brancas ao redor dos bráquetes. Prevenir a desmineralização durante o tratamento ortodôntico ainda é grande desafio ${ }^{10}$.

Uma terapêutica para prevenir ou tratar doenças da cavidade bucal, como cáries dentárias e doenças periodontais, é o probiótico, pois apresenta potencial de modificar a microbiota bucal devido a uma mudança na atividade do biofilme provocada pela alteração da composição microbiana e a reação resultante do hospedeiro ${ }^{11}$. Esses microrganismos estão relacionados na atualidade a benefícios à saúde bucal devido, dentre outros fatores, à produção de substâncias inibitórias do crescimento de Streptococcus mutans ${ }^{12}$.

Os probióticos quando associados a tratamentos convencionais podem melhorar a disbiose microbiana e promover melhora significativa no controle de doenças orais ${ }^{13}$. Essa recente e promissora alternativa para combater as infecções orais, a partir do uso de bactérias inofensivas, é denominada bacterioterapia ${ }^{14}$, o efeito bacterapêutico promovido pelos probióticos pode representar uma importante alternativa para se evitar o aparecimento de manchas brancas no esmalte após uso de aparelho ortodôntico fixo. Partindo desse pressuposto, a proposta do presente estudo foi avaliar a ação terapêutica de produtos lácteos contendo 
probiótico sob a presença de biofilme misto de Streptococcus mutans e $S$. salivarius e sua possível adesão aos bráquetes ortodônticos.

Para avaliar se o Lactobacillus acidophilus (La-5) era capaz de realizar bacterioterapia diante de biofilme de Streptococcus mutans e $S$ salivarius, foram realizados testes de halo de inibição e disco de membrana.

No teste de halo de inibição, não se constatou ação bacterapêutica em nenhum produto avaliado, o que confirma que o probiótico não apresenta ação bactericida ou bacteriostática. Esses achados corroboram a literatura pertinente no que diz respeito a usar probióticos como métodos auxiliares no controle e tratamento de algumas doenças odontológicas, tendo indicação profilática e não terapêutica ${ }^{14}$.

No teste de membrana, o objetivo foi avaliar o efeito de probiótico sobre a superfície da membrana que continha Streptococcus mutans e salivarius. As membranas são utilizadas quando se deseja avaliar a ação bactericida e/ou bacteriostática de determinados produtos, nesse caso, bacterapêutico, que é o uso terapêutico de culturas microbianas (geralmente bacilos Baciloterapia). No presente estudo, não foi possível provar essa ação de bacterioterapia isolado. Segundo Twetman ${ }^{15}$, é razoável considerar o uso da bacterioterapia como um possível complemento para a associação aos métodos existentes baseados em evidências para controlar e prevenir a cárie; já que o sinergismo que o probiótico faz com o S. mutans não chega a ter uma competição e sim uma coexistência dos dois. Já no estudo de Keller et al. ${ }^{16}$, o qual avaliou a longo prazo cáries radiculares, os resultados indicaram que o probiótico funcionou bem quando combinado com fluoreto.

0 protocolo usado para o teste de membrana foi feito seguindo o protocolo de Antonio et al. ${ }^{17}$, a escolha desse protocolo deu-se pelo fato de as membranas serem de uso mais fácil, não necessitarem de uma superfície como bloco dentário, por exemplo, para ser formada, e apresentarem menor risco de contaminação, no entanto apresentam custo mais elevado. No teste de adesividade, observou-se que o leite com probiótico e o leite fermentado com probiótico foram capazes de aderir aos bráquetes, pois houve crescimento de micro-organismo pela técnica de diluição seriada seguida de plaqueamento. Isso justifica investigações futuras com a finalidade de determinar a existência de alguma interação do probiótico com o biofilme, promovendo ou não a remineralização do esmalte dentário ao redor de bráquetes ortodônticos, tendo em vista que tanto os estreptococos do grupo mutans quanto os probióticos apresentam a propriedade de adesão18. Optou-se por testar a adesão dos produtos com probiótico ao bráquete metálico por estes serem os mais utilizados na rotina da clínica ortodôntica ${ }^{19}$.

Para realização do estudo, as culturas starters utilizadas foram a Lactococcus lactis ssp. Lactis e a Lactococcus lactis ssp. Cremoris (R-704), o probiótico utilizado foi o Lactobacillus acidophilus (La-5), em que a proporção final fosse de 7-8 log UFC/g de produto, quantidade essa já consagrada por muitos autores ${ }^{20,21}$, tornando assim os produtos lácteos viáveis. Estirpes de Lactobacillus rhamnosus, L. reuteri, L. casei e Bifidobacterium spp. apresentaram potencial para modificar a colonização de bactérias cariogênicas e com isso prevenir as cáries dentárias ${ }^{16}$. No entanto, Shin et al.22 afirmaram que L. lactis pode ser um probiótico útil, pois apresenta atividade antimicrobiana, visto que produz bacteriocinas.

A ausência de condições que mimetizem aquelas encontradas na cavidade bucal, como a presença de saliva, higiene oral, e a heteriogenicidade da microbiota bucal, também constituem uma limitação. Por isso se justifica a realização de outros estudos em que possa se avaliar a possível interação da microbiota oral com os probióticos.

\section{CONCLUSÃO}

Conclui-se com a realização deste estudo que: 
- Os leites bovino e fermentado contendo probiótico não são capazes de promover bacterioterapia sob pool de cepas ATCC de SS e SM;

- Leite bovino e leite fermentado com probiótico apresentam adesividade aos bráquetes; e

- Leite bovino e leite fermentado sem probiótico não apresentam adesividade aos bráquetes.

\section{REFERÊNCIAS}

1. Julien KC, Buschang PH, Campbell PM. Prevalence of white spot lesion formation during orthodontic treatment. Angle Orthod. 2013 Jul;83(4):641-7. http://dx.doi.org/10.2319/071712-584.1. PMid:23289733.

2. Lucchese A, Gherlone E. Prevalence of white-spot lesions before and during orthodontic treatment with fixed appliances. Eur J Orthod. 2013 Oct;35(5):664-8. http://dx.doi.org/10.1093/ejo/cjs070. PMid:23045306.

3. Robinson C. Fluoride and the caries lesion: interactions and mechanism of action. Eur Arch Paediatr Dent. 2009 Sep;10(3):136-40. http://dx.doi.org/10.1007/BF03262674. PMid:19772842.

4. Wolff MS, Larson C. The cariogenic dental biofilm: good, bad or just something to control? Braz Oral Res. 2009;23(Suppl 1):31-8. http://dx.doi.org/10.1590/S1806-83242009000500006. PMid:19838556.

5. Sanpei S, Endo T, Shimooka S. Caries risk factors in children under treatment with sectional brackets. Angle Orthod. 2010 May;80(3):509-14. http://dx.doi.org/10.2319/072909-431.1. PMid:20050745.

6. Beyth N, Redlich M, Harari D, Friedman M, Steinberg D. Effect of sustained-release chlorhexidine varnish on Streptococcus mutans and Actinomyces viscosus in orthodontic patients. Am J Orthod Dentofacial Orthop. 2003 Mar;123(3):345-8. http://dx.doi.org/10.1067/mod.2003.19. PMid:12637907.

7. Corbitt M, Campagnolo N, Staines D, Marshall-Gradisnik S. A systematic review of probiotic interventions for gastrointestinal symptoms and irritable bowel syndrome in Chronic Fatigue Syndrome/Myalgic Encephalomyelitis (CFS/ME). Probiotics Antimicrob Proteins. 2018 Sep;10(3):46677. http://dx.doi.org/10.1007/s12602-018-9397-8. PMid:29464501.

8. Guarner F, Perdigon G, Corthier G, Salminen S, Koletzko B, Morelli L. Should yoghurt cultures be considered probiotic? Br J Nutr. 2005 Jun;93(6):783-6. http://dx.doi.org/10.1079/BJN20051428. PMid:16022746.

9. Meurman JH. Probiotics: do they have a role in oral medicine and dentistry? Eur J Oral Sci. 2005 Jun;113(3):188-96. http://dx.doi.org/10.1111/j.1600-0722.2005.00191.x. PMid:15953242.

10. Tufekci E, Dixon JS, Gunsolley JC, Lindauer SJ. Prevalence of white spot lesions during orthodontic treatment with fixed appliances. Angle Orthod. 2011 Mar;81(2):206-10. http://dx.doi.org/10.2319/051710-262.1. PMid:21208070.

11. Allaker RP, Ian Douglas CW. Non-conventional therapeutics for oral infections. Virulence. 2015;6(3):196-207. http://dx.doi.org/10.4161/21505594.2014.983783. PMid:25668296.

12. Nikawa H, Makihira S, Fukushima H, Nishimura H, Ozaki Y, Ishida K, et al. Lactobacillus reuteri in bovine milk fermented decreases the oral carriage of mutans streptococci. Int J Food Microbiol. 2004 Sep;95(2):219-23. http://dx.doi.org/10.1016/j.ijfoodmicro.2004.03.006. PMid:15282133.

13. Allaker RP, Stephen AS. Use of probiotics and oral health. Curr Oral Health Rep. 2017;4(4):309-18. http://dx.doi.org/10.1007/s40496-017-0159-6. PMid:29201598.

14. Caglar K, Kutluk T, Varan A, Koray Z, Akyuz C, Yalcin B, et al. Leptin and neuropeptide Y plasma levels in children with cancer. J Pediatr Endocrinol Metab. 2005 May;18(5):485-9.

http://dx.doi.org/10.1515/JPEM.2005.18.5.485. PMid:15921178. 
15. Twetman S. Are we ready for caries prevention through bacteriotherapy? Braz Oral Res. 2012;26(Suppl 1):64-70. http://dx.doi.org/10.1590/S1806-83242012000700010. PMid:23318746.

16. Keller MK, Hasslof P, Dahlen G, Stecksen-Blicks C, Twetman S. Probiotic supplements (Lactobacillus reuteri DSM 17938 and ATCC PTA 5289) do not affect regrowth of mutans streptococci after fullmouth disinfection with chlorhexidine: a randomized controlled multicenter trial. Caries Res. 2012;46(2):140-6. http://dx.doi.org/10.1159/000337098. PMid:22472585.

17. Antonio AG, Iorio NL, Farah A, Santos KR No, Maia LC. Effect of Coffea canephora aqueous extract on microbial counts in ex vivo oral biofilms: a case study. Planta Med. 2012 May;78(8):755-60. http://dx.doi.org/10.1055/s-0031-1298435. PMid:22532021.

18. Kolenbrander PE, Andersen RN, Baker RA, Jenkinson HF. The adhesion-associated sca operon in Streptococcus gordonii encodes an inducible high-affinity ABC transporter for Mn2+ uptake. J Bacteriol. 1998 Jan;180(2):290-5. PMid:9440518.

19. Menezes LM, Campos LC, Quintao CC, Bolognese AM. Hypersensitivity to metals in orthodontics. Am J Orthod Dentofacial Orthop. 2004 Jul;126(1):58-64. http://dx.doi.org/10.1016/j.ajodo.2003.05.014. PMid:15224060.

20. Caglar E, Kuscu OO, Cildir SK, Kuvvetli SS, Sandalli N. A probiotic lozenge administered medical device and its effect on salivary mutans streptococci and lactobacilli. Int J Paediatr Dent. 2008 Jan;18(1):35-9. http://dx.doi.org/10.1111/j.1365-263X.2007.00866.x. PMid:18086024.

21. Gizani S, Petsi G, Twetman S, Caroni C, Makou M, Papagianoulis L. Effect of the probiotic bacterium Lactobacillus reuteri on white spot lesion development in orthodontic patients. Eur J Orthod. 2016 Feb;38(1):85-9. http://dx.doi.org/10.1093/ejo/cjv015. PMid:25840585.

22. Shin HS, Baek DH, Lee SH. Inhibitory effect of Lactococcus lactis on the bioactivity of periodontopathogens. J Gen Appl Microbiol. 2018 May;64(2):55-61. http://dx.doi.org/10.2323/jgam.2017.06.003. PMid:29367491.

\section{CONFLITOS DE INTERESSE}

Os autores declaram não haver conflitos de interesse.

\section{*AUTOR PARA CORRESPONDÊNCIA}

Matheus Melo Pithon, UFRJ - Universidade Federal do Rio de Janeiro, Faculdade de Odontologia, Departamento de Odontopediatria e Ortodontia, CP 68066, Cidade Universitária, 21941-971 Rio de Janeiro - RJ, Brasil, e-mail: matheuspithon@gmail.com

Recebido: Setembro 27, 2019

Aprovado: Novembro 11, 2019 